\title{
A PROPRIEDADE COMUNAL A PARTIR DO CASO XUCURU DA CORTE INTERAMERICANA DE DIREITOS HUMANOS
}

VANESSA DE CASTRO ROSA ${ }^{1}$

UEMG, BRASIL

http://orcid.org/0000-0002-8370-0373

MARINA DIAS MASCHIO

UEMG, BRASIL

https://orcid.org/0000-0002-7768-045X

\begin{abstract}
RESUMO: $O$ Brasil violou o direito à propriedade indígena coletiva dos povos Xucurus e foi condenado internacionalmente pela Corte Interamericana de Direitos Humanos. O presente trabalho analisa a natureza jurídica da propriedade comunal a partir do Caso do Povo Indígena Xucuru após a condenação do Estado brasileiro pela Corte Interamericana de Direitos Humanos por violação desse direito, bem como verifica a interpretação do conceito de propriedade comunal pelo direito interno e examina a compatibilidade desse com o direito internacional. Para tanto, utilizou-se como metodologia o estudo de caso da sentença da Corte com fito de investigar minuciosamente os fundamentos e pressupostos estabelecidos para fixação desse conceito e, ainda, o método comparativo entre as normas de direito internacional e o ordenamento jurídico pátrio. Dessa maneira, verificou-se o aspecto coletivo da propriedade indígena. No entanto, esse aspecto não tem sido exercido no direito brasileiro, apesar de possuir compatibilidade no tocante à teoria do indigenato, baseada no direito originário e congênito de suas terras. A não aplicabilidade do conceito de propriedade indígena como coletiva acarretou a esses povos uma grande dificuldade de pleno acesso, uso e gozo de seus direitos às terras, diante da desvalorização dos aspectos especiais da propriedade comunal, fundamentados na ancestralidade.
\end{abstract}

PALAVRA-CHAVE: Propriedade comunal, Povo Indigena Xucuru, Corte Interamericana de Direitos Humanos, Propriedade Indígena.

ABSTRACT: Brazil has violated the right to collective indigenous property of the Xucurus people and was internationally condemned by the Inter-American Court of Human Rights. This work analyzes the legal nature of communal property from the case of the Xucuru Indigenous People after the condemnation of the Brazilian State by the Inter-American Court of Human Rights for violation of this right, as well as verifies the interpretation of the concept of communal property by domestic law and examines its compatibility with international law. To this end, the case study of the Court sentence was used as a methodology in order to thoroughly investigate the fundamentals and assumptions established for the fixation of this concept and also the comparative method between the norms of international law and the national legal system. Thus, the collective aspect of indigenous property was verified, however, this aspect has not been exercised in Brazilian law, despite being compatible with the theory of indigenate, based on the original and congenital right to their lands. The non-applicability of the concept of indigenous

\footnotetext{
${ }^{1}$ Doutora em Direito pela Mackenzie. Professora de Direito Ambiental e Agrário da Universidade Estadual de Minas Gerais da unidade Frutal. E-mail: vanisros@hotmail.com

2 Bacharela em Direito pela Universidade Estadual de Minas Gerais. E-mail: marina dias maschio@hotmail.com
} 
Espaço Ameríndio

property as a collective one caused these peoples a great difficulty in fully accessing, using and enjoying their rights to the lands, given the devaluation of the special aspects of communal property, grounded on ancestry.

KEYWORDS: Communal property, Xucuru People, Inter-American Court of Rights, Indigenous Property. 
Espaço Ameríndio

\section{Introdução}

O Estado brasileiro foi submetido à jurisdição da Corte Interamericana de Direitos Humanos e em 5 de fevereiro de 2018 foi condenado internacionalmente por violação do direito à propriedade comunal (coletiva) do povo indígena Xucuru.

A propriedade comunal indígena é um direito humano que assegura a posse legítima das terras, bem como o desfruto de seus recursos naturais, baseado na relação cultural, espiritual e material desses povos com seus territórios ancestrais, para o exercício pleno de toda coletividade indígena sobre todos os aspectos desta.

O presente trabalho tem como escopo principal a análise da propriedade indígena comunal e seu conceito através das normas de direito internacional e o julgado da Corte Interamericana, bem como a interpretação e compatibilidade desse conceito e a aplicação da propriedade indígena no Brasil.

A interpretação da propriedade indígena pela jurisprudência nacional tem acarretado a esses povos uma drástica insegurança jurídica em relação aos seus direitos de acesso às terras, diante da deturpada interpretação desse conceito no direito interno, bem como a exorbitante demora pelo poder público no procedimento demarcatório dessas terras.

Desse modo, é necessário investigar a natureza jurídica da propriedade indígena no direito brasileiro a partir do caso Xucuru, julgado pela Corte Interamericana de Direitos Humanos, bem como distinguir a propriedade comunal da propriedade privada civilista e sua devida aplicabilidade no direito interno.

Neste viés, faz-se necessário o reconhecimento e a aplicação do conceito de propriedade comunal de acordo com as normas de direito internacional e sua jurisprudência, pois se trata de direito humano assegurado por tratados e convenções, utilizados pelo Brasil.

Como método de procedimento adotou-se o estudo de caso para investigação dos argumentos e pressupostos usados para fundamentar a decisão do caso Povo indígena Xucuru x República Federativa do Brasil, julgado pela Corte Interamericana de Direitos Humanos e o método comparativo, buscando-se entender o conceito internacional advindo do julgamento do caso Xucuru, bem como a comparação deste com o do direito interno, compreendendo suas divergências e suas consequências jurídicas.

\section{O caso Xucuru}

O povo indígena Xucuru é composto por comunidades indígenas que remontam ao século XVI no estado do Pernambuco. Documentos históricos descrevem essas áreas que foram ocupadas pelos Xucurus no século XVIII, que, contemporaneamente, encontram-se distribuídos pelo município de Pesqueira, no interior do Estado do Pernambuco, 
Atualmente, o chamado Povo Xukuru de Ororubá é constituído por 2.354 famílias, as quais vivem em 2.265 casas. Dentro da terra indígena Xucuru vivem 7.726 indígenas, distribuídos em 24 comunidades dentro de um território de aproximadamente 27.555 hectares, no município de Pesqueira, estado de Pernambuco. Além disso, aproximadamente 4.000 indígenas vivem fora da terra indígena na cidade de Pesqueira (OEA, 2018, p. 1617).

Esses povos iniciaram o procedimento administrativo de demarcação de terras no ano de 1989, o qual findou-se apenas em 2005, gerando grandes efeitos jurídicos para o Estado Brasileiro diante de tamanha demora.

À vista da insegurança jurídica ocasionada pelo tempo no procedimento de demarcação e pela ocupação de pessoas não indígenas nessas áreas propriamente indígenas, bem como a dificuldade em fazer com que esses terceiros fossem retirados desses territórios, o caso Xucuru foi submetido à jurisdição internacional da Corte Interamericana de Direitos Humanos, sendo que em 5 de fevereiro de 2018 o Brasil foi condenado internacionalmente pela violação da propriedade comunal (coletiva) indígena.

A condenação fixada ao Estado brasileiro consistiu no pagamento de indenização por dano imaterial no valor de US\$1.000.000,00 (um milhão de dólares dos Estados Unidos da América), que deverá ser destinado a um fundo comunitário, o qual será criado, conforme ordenação da Corte, no prazo não superior a 18 meses a partir da notificação da Sentença, sendo este fundo um complemento aos outros benefícios presentes ou futuros que caibam aos povos indígenas em relação aos deveres gerais do Estado (OEA, 2018, p. 52).

Ademais, o Estado deve garantir o direito de propriedade coletiva do Povo Xucuru sobre seu território, protegendo esses povos de invasões, interferências ou danos por terceiros não indígenas ou por ele próprio. Para tanto, deve concluir o processo de desintrusão desse território indígena, efetuando o pagamento das indenizações de boa-fé pendentes, de forma que garanta o pleno e efetivo domínio sobre seu território, também no prazo de 18 meses.

Ainda, estabeleceu a sentença que o Estado promovesse com a publicação, no prazo de seis meses, de um resumo oficial da Sentença, elaborado pela Corte, e também seu inteiro teor, devendo ficar disponível pelo período mínimo de um ano, os quais encontram-se presentes no Diário Oficial da União, tendo sido publicados na data de 13/09/2018.

$\mathrm{Na}$ atualidade, $\mathrm{o}$ presente caso encontra-se em fase de cumprimento de sentença, tendo sido fixado prazo de 18 meses para efetivo cumprimento, prazo que está ainda em aberto, sendo que a Corte supervisionará o cumprimento integral da Sentença e, quando ocorrido, dará por concluído o caso. 


\section{A propriedade indígena no direito internacional}

A Convenção Americana de Direitos Humanos, também conhecida como Pacto São José da Costa Rica, é um dos principais tratados internacionais de direitos humanos, o qual estabeleceu que a Comissão e a Corte são os órgãos competentes para conhecer dos assuntos relacionados com o cumprimento dos compromissos assumidos pelos Estados Partes da Convenção.

Esse tratado foi ratificado pelo Brasil em 1992 por meio do decreto presidencial $n^{\circ} 678 / 1992$, sendo reconhecida a competência da Corte posteriormente em 1998, promulgado quatro anos após, em 2002, pelo Decreto 4.463/2002, momento em que fora expressamente aceita a competência da Corte para aplicação da Convenção, conforme seu artigo 62, bem como o artigo $1^{\circ}$ do decreto presidencial de 2002.

A Convenção, em seu artigo 21 , dispõe sobre o direito à propriedade privada, o qual recebe da Corte um tratamento evolutivo para a garantia da propriedade comunal dos povos indígenas (OEA, 1969).

A interpretação evolutiva foi utilizada após o advento da democracia na América Latina, pois permitiu uma releitura dos direitos previstos no Pacto de São José da Costa Rica, fundamentada na Convenção de Viena, a qual regula as interpretações dos tratados internacionais e dispõe em seu artigo 31.1 que essa interpretação deve ser realizada de acordo com a boa fé e à luz de seu objetivo e finalidade, bem como na Convenção Americana em seu artigo 29, b, que proíbe interpretações que limitem direitos (LINS JÚNIOR; LACERDA, 2017, p. 259).

Esse aspecto evolutivo evidencia-se na aplicabilidade do direito de propriedade que leva em conta a ancestralidade dos povos indígenas com seus territórios, tendo em vista a adoção de interpretações mais adequadas dos tratados às necessidades atuais.

$\mathrm{O}$ direito à propriedade comunal (coletiva) dos povos indígenas é um direito humano fundamental que deve ser observado pelos Estados que reconheceram a competência da Corte para a delimitação e demarcação de terras, considerando sempre o uso tradicional e a ancestralidade de seus povos com seu território.

O primeiro julgado da Corte Interamericana que aplicou o aspecto evolutivo ao reconhecer da propriedade comunal dos povos indígenas sobre seus territórios, levando em conta o uso tradicional e a ancestralidade, foi o caso Awas Tingui contra Nicarágua, nos seguintes termos:

Entre os indígenas existe uma tradição comunitária sobre uma forma comunal da propriedade coletiva da terra, no sentido de que o pertencimento desta não se centra em um indivíduo, mas no grupo e sua comunidade. Os indígenas, pelo fato de sua própria existência, têm direito a viver livremente em seus próprios territórios; a relação próxima que os indígenas mantêm com a terra deve de ser reconhecida e compreendida como a base fundamental de suas culturas, sua vida espiritual, sua 
integridade e sua sobrevivência econômica. Para as comunidades indígenas, a relação com a terra não é meramente uma questão de posse e produção, mas sim um elemento material e espiritual do qual devem gozar plenamente, inclusive para preservar seu legado cultural e transmiti-lo às futuras gerações (OEA, 2001, p. 78).

A propriedade comunal possui uma relação entre os indígenas e suas terras e vai além do conceito de propriedade comum, pois é uma tradição coletiva que leva em conta os aspectos ancestrais, culturais, espirituais, bem como a integridade e sobrevivência econômica dos que ali vivem. A propriedade para os indígenas ultrapassa a relação de posse e produção com a terra, haja vista possuir elementos culturais e espirituais os quais devem ser transmitidos às gerações futuras, preservando os valores e a cultura do povo indígena.

Após 17 anos de discussão e tramitação, em 15 de junho de 2016, foi aprovado pela Assembleia Geral da Organização dos Estados Americanos (OEA) a Declaração Americana sobre os Direitos dos Povos Indígenas (DADPI), com conteúdo compatível com a legislação e políticas voltadas aos povos indígenas no Brasil, como, por exemplo, o direito às terras, o que prioriza o avanço na promoção e proteção efetiva dos direitos desses povos nas Américas (BRASIL, [2016]).

A Declaração dispõe que os direitos dos povos indígenas são fundamentais e de grande importância histórica para as Américas, pois contribuíram e contribuem com o desenvolvimento, a pluralidade e a diversidade cultural. Além disso, reitera o compromisso com o bem-estar econômico e social dos povos indígenas, reforçando a obrigação dos Estados de respeitar seus direitos e sua identidade cultural (OEA, 2016).

Assim, a Declaração é expressa, em seu artigo XXV, no dever dos Estados estabelecerem regimes especiais de proteção destas terras e de assegurarem a relação espiritual, cultural e material dos povos indígenas com suas terras, territórios e recursos, bem como o direito à posse, utilização e controle das terras, territórios e recursos (OEA, 2016).

Diante das diversas adversidades sofridas diariamente pelos povos indígenas, bem como da tamanha discriminação desses povos, as reivindicações indígenas chegaram ao cenário internacional e foram centralizadas na aprovação da Declaração das Nações Unidas sobre os Direitos dos Povos Indígenas pela Assembleia Geral da Organização das Nações Unidas (ONU) em 13 de setembro de 2007.

Os principais temas abordados pela Declaração da ONU foram a autodeterminação, que consiste no direito de determinações livres sobre aspectos de desenvolvimento econômico, social e cultural; o direito ao consentimento livre, prévio e informado, que garante aos povos indígenas o direito de consultas prévias antes de qualquer providência a ser tomada pelos entes políticos; o direito à reparação pelo furto de suas propriedades, o qual incluiu reparação aos povos indígenas em relação a qualquer propriedade (cultural, religiosa, intelectual, ancestral); o direito à comunicação, que resguardou o direito de manter seus próprios meios 
de comunicação, o qual garante incorporação na mídia para reflexão da diversidade cultural dos povos indígenas (MATHIAS; YAMADA, 2010).

Nos termos da Declaração, é dever dos Estados assegurarem o reconhecimento, conforme o procedimento demarcatório das terras tradicionalmente ocupadas e a proteção jurídica dessas terras, territórios e recursos, sendo necessário a subordinação aos costumes, às tradições e aos sistemas de usufruto da terra dos povos indígenas (ONU, 2007).

Ocorre que o próprio Estado, ao proteger e reconhecer esses direitos, viola as normas internacionais e interpreta de forma deturpada, gerando desigualdades e racismo institucional, pois os sistemas executivo, legislativo e judiciário negam esses direitos dos povos indígenas, além da consequente violência, intolerância e discriminação ligada às lutas pelos direitos de terras e territórios e recursos inerente a elas.

Ao tratar da interpretação da ONU, a Declaração reconheceu como instrumento garantidor de acesso à terra a autonomia política aos povos indígenas e também o direito de participação política nas decisões dos Estados nacionais, garantindo o direito à terra sob um viés não econômico e capitalista.

O direito de manter, controlar, proteger e desenvolver seu patrimônio cultural, definido no artigo 31, está ligado justamente à preservação da reparação pelos eventuais furtos do patrimônio desses povos, sendo que seus conhecimentos tradicionais e suas expressões culturais, científicas e tecnológicas, bem como a manifestação de suas ciências, como recursos humanos e genéticos, as sementes, os medicamentos, o conhecimento sobre a fauna e a flora, tradições literais, esportivas, visuais e artísticas, devem ser, juntamente entre os povos indígenas e seus Estados, reconhecidos e protegidos.

Verifica-se então que a Declaração da ONU adotou uma interpretação de maior autonomia aos povos indígenas, pois "a autonomia política conferida pela ONU aos povos indígenas está calcada no direito de criar e manter suas próprias instituições políticas, ao mesmo tempo em que garante o direito de participação na política de Estado" (TERRA DE DIREITOS, 2015 , p. 22).

Essa autonomia tratada pela Declaração da ONU abrange a propriedade indígena de forma muito mais favorável aos povos indígenas, pois no Brasil, conforme a Constituição Federal, as terras indígenas são de propriedade do Estado com usufruto exclusivo dos povos indígenas.

No entanto, as normas redigidas pelas entidades internacionais no âmbito do direito internacional, como a ONU, são caracterizadas como normas soft law, ou seja, normas de maior flexibilidade:

A soft law pode ser definida como um conjunto de normas (standards normativos) de categoria residual cujo escopo é criar vinculações exortatórias, em oposição clara às vinculações obrigatórias próprias da hard law criando, deste modo, uma expectativa de cumprimento baseada na autonomia da vontade e na 
boa-fé típica dos acordos convencionados cuja raiz é o mútuo consentimento (GREGÓRIO, 2016, p. 3).

Outro importante documento internacional é a Convenção 169 da Organização Internacional do Trabalho (OIT), aprovada em 1989, que trouxe benefícios importantes aos povos ali tratados, como "assumir o controle de suas próprias instituições e formas de vida e seu desenvolvimento econômico e manter e fortalecer suas identidades, línguas e religiões, dentro dos Estados em que vivem" (OIT, 1989).

Os principais avanços da Convenção são relacionados ao objetivo de tencionar os Estados a reconhecer efetivamente os direitos à terra. Além disso, adotou postura de servir como instrumento de interpretação de direitos reconhecidos pelos Estados e ainda o direito de regresso e de não mudança de suas terras.

Com a ratificação da Convenção 169 da OIT, o Brasil passou a adotar uma visão doutrinária de modelo de Estado Pluriétnico, o qual tem guarida constitucional, haja vista que a própria Constituição obrigou os Estados a garantir o pleno exercício dos direitos culturais, bem como a obrigação de proteção às manifestações das culturas populares, indígenas e afro-brasileiras, e às de outros grupos participantes do processo civilizatório nacional (HEEMANN, 2017, p. 6).

A interpretação que deve ser utilizada pelos Estados que fazem parte da Convenção deve levar em conta, ao aplicar os direitos nela existentes, a cultura e os valores espirituais que os povos indígenas possuem com suas terras e territórios, conforme destaca o próprio artigo 13 da Convenção (OIT, 1989).

Ao tratar da propriedade indígena e do direito às terras e territórios, a Convenção adotou um capítulo próprio para destacar esses direitos, reconhecendo aos povos indígenas o direito de propriedade e posse sobre suas terras tradicionalmente ocupadas e, ainda, a possibilidade da adoção de medidas para resguardar os direitos de seus povos de utilizar as terras que não estão exclusivamente ocupadas, mas que possuam acesso para suas atividades tradicionais e de subsistência.

Tais direitos deverão ser assegurados e protegidos pelos Estados que tomarão as medidas necessárias para determinação efetiva da posse dessas terras, bem como sua proteção, instituindo procedimentos adequados no sistema jurídico nacional, qual seja, o procedimento demarcatório de terras, para solução das reivindicações de posse e propriedade dos povos indígenas, conforme previsto em seu artigo 14 (OIT, 1989).

Os conceitos relacionados aos direitos às terras adotados pela Convenção 169 estão em total acordo com a interpretação da Corte Interamericana de Direitos Humanos, pois reconhecem a proteção da relação mantida entre esses povos e suas terras tradicionalmente ocupadas e possuídas (SCHETTINI, 2012, p. 71) e por isso deve servir como instrumento normativo de interpretações pela Corte em suas decisões.

A Corte, ao embasar suas interpretações de acordo com a Declaração das Nações Unidas sobre Direitos dos povos Indígenas e a 
Convenção 169 da OIT, entende que "esses povos têm o direito de possuir e controlar seus territórios e os recursos naturais que nele se encontram sem nenhum tipo de interferência externa, cabendo aos Estados garantirIhes o direito de administrar e explorar seus territórios de acordo com sua tradição comunitária" (SCHETTINI, 2012, p. 71-72).

Esse conceito comunitário adota uma interpretação não individualista da propriedade, haja vista que relacionamento entre seus povos e seus territórios não possuem um viés unicamente econômico, superando essa visão com a terra baseada nas questões econômicas e incitando os Estados a interpretações que não sejam assim atreladas (TERRA DE DIREITOS, 2015, p. 24),

A Convenção $\mathrm{n}^{\circ} 169$ também estabelece, em seu artigo 16, que os povos indígenas não devem ser expulsos de seus territórios tradicionais, regra esta não absoluta, pois contém diversas exceções em seus parágrafos, sendo que, em última hipótese, tornando-se impossível o retorno desses povos aos seus territórios, deverão ser indenizados em ação de regressiva (OIT, 1989).

Tal procedimento busca efetivar que o direito às terras não seja violado, sendo que a sua impossibilidade de manutenção nas terras seja indenizada por procedimento adequado que garanta outras terras de igual qualidade e com estatuto jurídico igual e, ainda, que cubram as necessidades e garantam o desenvolvimento futuro, podendo, inclusive, essa indenização ser realizada em dinheiro ou bens, a qual será concedida também com garantias apropriadas.

\section{A propriedade comunal na corte interamericana}

A Corte Interamericana de Direitos Humanos vem consolidando uma concepção de propriedade indígena que supera o conceito de propriedade privada, através de uma interpretação evolutiva do artigo 21 da Convenção Americana, a qual passa a interpretar a propriedade com um viés coletivo, conforme a já mencionada sentença da Corte no Caso da Comunidade Mayagna (Sumo) Awas Tingni vs. Nicarágua:

Através de uma interpretação evolutiva dos instrumentos internacionais de proteção de direitos humanos, levando em consideração as normas de interpretação aplicáveis e, conforme o artigo 29.b da Convenção - que proíbe uma interpretação restritiva dos direitos -, esta Corte considera que o artigo 21 da Convenção protege o direito à propriedade num sentido que compreende, entre outros, os direitos dos membros das comunidades indígenas no contexto da propriedade comunal (OEA, 2001, p. 78).

O caso da Comunidade Mayagna (Sumo) Awas Tingni vs. Nicarágua, apresentado pela Comissão Interamericana de Direitos Humanos em 4 de junho de 1998 à Corte, foi o primeiro julgado pela Corte ao reconhecer a propriedade comunal e trouxe em seu julgamento características e 
interpretações emblemáticas para as comunidades indígenas. O conceito adotado, a partir de então pela Corte, com relação à interpretação da propriedade indígena coletiva, levou em conta diversos aspectos relevantes no relacionamento dos povos indígenas com suas terras, fundamentados na relação da ancestralidade.

O conceito de propriedade abordado pela Corte considerou a tradição comunitária dos povos indígenas com seus territórios. Essa coletividade está ligada ao aspecto não individualista em relação ao pertencimento dessas terras, territórios e recursos, pois estes são de todos. Além disso, o relacionamento que esses povos mantêm com suas terras está conectado, de acordo com a perspectiva fundamental, à ótica de sua cultura, sua vida espiritual, sua integridade e também sobrevivência econômica.

Ao estabelecer critérios para o conceito dessa propriedade coletiva, o antropólogo e sociólogo Rodolfo Stavenhagen Gruenbaum apontou:

Há dois conceitos de terra coletiva: o território, em sua generalidade, que a comunidade considera comum, embora existam mecanismos internos para atribuir utilização e ocupação eventual a seus membros e que não permite alienação a pessoas que não são membros da comunidade; e o que são áreas exclusivas de utilização coletiva, "commons", que não se dividem em parcelas. Quase todas as comunidades indígenas têm uma parte de "commons", de uso coletivo, e depois outra parte que pode ser dividida e atribuída a famílias ou a unidades domésticas. Entretanto, é mantido o conceito de propriedade coletiva, que, quando não está titulada, é questionada por outros, inclusive muitas vezes pelo Estado. Quando há problemas, surge a necessidade de que existam títulos de propriedade, porque a comunidade se arrisca a perder tudo. A história da América Latina tem consistido em um despojo praticamente permanente de comunidades indígenas por interesses externos (OEA, 2001, p. 25).

A primeira interpretação diz respeito à generalidade do território, ou seja, o que é considerado comum, embora haja atribuições para utilização e ocupação eventual aos membros dessas comunidades, sendo que não é permitido a alienação dessas a terceiros não participantes dessas comunidades.

Já a segunda, ao tratar do coletivo, aborda a exclusividade da utilização coletiva como algo indivisível, pertencentes a todos, também denominada commons. Esse segundo conceito está presente em quase todas comunidades indígenas em uma parcela, ou seja, um espaço coletivo, indivisível, de todos, bem como uma segunda parcela atribuída às famílias ou unidades domésticas.

Nesse sentido, em seu testemunho, Jaime Castillo Felipe, membro da Comunidade Awas Tingni, destacou que as terras são ocupadas e 
exploradas por toda a comunidade, de modo que ninguém é individualmente dono da terra e os recursos desta são coletivos. Se a pessoa não pertencer à comunidade, não poderá explorar a terra e não existe o direito de expulsar alguém da comunidade (OEA, 2001, p. 19).

O direito à terra "ultrapassa este conceito tradicional no qual prima a relação individual. Por outro lado, a propriedade comunal ou coletiva cumpre da melhor maneira a exigência ineludível da função social porque esta é parte de sua natureza" (OEA, 2001, p. 93).

Nesse raciocínio, ao adotar a interpretação evolutiva da propriedade privada constante no artigo 21 da Convenção Americana, a Corte garante a esses povos a propriedade comunal, pois deixar de lado os usos e costumes destes povos é desigual e não razoável, tendo em vista que a relação deles com suas terras é especial e, por isso, merece ser analisada de acordo com suas especialidades.

De igual modo, a Corte reafirmou tal entendimento no caso brasileiro:

A Corte recorda que o artigo 21 da Convenção Americana protege 0 estreito vínculo que os povos indígenas mantêm com suas terras bem como com seus recursos naturais e com os elementos incorporais que neles se originam. Entre os povos indígenas e tribais existe uma tradição comunitária sobre uma forma comunal da propriedade coletiva da terra, no sentido de que a posse desta não se centra em um indivíduo, mas no grupo e sua comunidade. Essas noções do domínio e da posse sobre as terras não necessariamente correspondem à concepção clássica de propriedade, mas a Corte estabeleceu que merecem igual proteção do artigo 21 da Convenção Americana. Desconhecer as versões específicas do direito ao uso e gozo dos bens, dadas pela cultura, usos, costumes e crenças de cada povo, equivaleria a afirmar que só existe uma forma de usar os bens, e deles dispor, o que, por sua vez, significaria tornar ilusória a proteção desses coletivos por meio dessa disposição. Ao se desconhecer o direito ancestral dos membros das comunidades indígenas sobre seus territórios, se poderia afetar outros direitos básicos, como o direito à identidade cultural e à própria sobrevivência das comunidades indígenas e seus membros (OEA, 2018, p. 29).

Ademais, importante salientar que os direitos dos povos indígenas são preexistentes e não dependem de titulação de propriedade ou de atos administrativos e judiciais que os reconheça, pois eles não estão condicionados a qualquer tipo de reconhecimento estatal ou qualquer outro tipo idôneo e formal, pois são originários.

Reafirmando a independência de titulação de propriedade, a Corte aponta que a simples posse tradicional tem efeito equivalente aos títulos de pleno domínio concedidos pelos Estados, mas ela confere aos povos 
indígenas o direito de exigir esse reconhecimento pelo Estado, bem como seu respectivo registro.

Ademais, ressalta que aqueles povos que, independentemente de sua vontade, tenham perdido a posse que possuíam, não perdem o direito de propriedade, inclusive se estas não possuírem registro, salvo se transferidas a terceiros de boa-fé, resguardado o direito de regresso desses territórios em igual proporção e qualidade de terras.

Apesar da interpretação de independência de titulação para o direito de propriedade pelos povos indígenas, é dever do Estado promover a demarcação das terras e reconhecer os direitos originários, concedendo a eles, título de propriedade coletiva.

Além disso, deve promover a posse pacífica, sem qualquer tipo de interferências externas de terceiros não indígenas, bem como garantir os direitos desses povos em controlar efetivamente seus territórios e de usufruir de seus recursos naturais, pois o uso e gozo dessas terras não são benefícios, nem privilégios, mas sim um direito que integra os povos indígenas.

Nesse sentido, o julgado é emblemático:

1) a posse tradicional dos indígenas sobre suas terras tem efeitos equivalentes aos do título de pleno domínio concedido pelo Estado; 2) a posse tradicional confere aos indígenas o direito de exigir o reconhecimento oficial de propriedade e seu registro; 3 ) os membros dos povos indígenas que, por causas alheias a sua vontade, tenham saído ou perdido a posse de suas terras tradicionais mantêm o direito de propriedade sobre elas, apesar da falta de título legal, salvo quando as terras tenham sido legitimamente transferidas a terceiros de boa-fé; 4) o Estado deve delimitar, demarcar e conceder título coletivo das terras aos membros das comunidades indígenas; 5) os membros dos povos indígenas que involuntariamente tenham perdido a posse de suas terras, e estas tenham sido trasladadas legitimamente a terceiros de boa-fé, têm o direito de recuperá-las ou a obter outras terras de igual extensão e qualidade; 6) o Estado deve garantir a propriedade efetiva dos povos indígenas e abster-se de realizar atos que possam levar a que os agentes do próprio Estado, ou terceiros que ajam com sua aquiescência ou sua tolerância, afetem a existência, o valor, o uso ou o gozo de seu território; 7) o Estado deve garantir o direito dos povos indígenas de controlar efetivamente seu território, e dele ser proprietários, sem nenhum tipo de interferência externa de terceiros; e 8) o Estado deve garantir o direito dos povos indígenas ao controle e uso de seu território e recursos naturais. Com relação ao exposto, a Corte afirmou que não se trata de um privilégio de usar a terra, o qual pode ser cassado pelo Estado ou superado por direitos à propriedade de terceiros, mas um direito dos integrantes de povos indígenas e tribais de obter a 
titulação de seu território, a fim de garantir o uso e gozo permanente dessa terra (OEA, 2018, p. 30).

Contudo, a inércia do Estado em garantir os direitos supracitados vem gerando no território nacional uma insegurança jurídica dos povos indígenas em relação às suas terras, pois "é necessário materializar os direitos territoriais dos povos indígenas mediante a adoção de medidas legislativas e administrativas para criar um mecanismo efetivo de delimitação, demarcação e titulação, que reconheça esses direitos na prática" (OEA, 2018, p. 30).

\section{A propriedade indígena no direito brasileiro e o indigenato}

A propriedade é um direito real originado de uma relação (jurídica) entre uma pessoa e a coisa, traduzindo apropriação de riquezas (valor econômico), tendo por objeto um bem material (corpóreo) ou imaterial (incorpóreo) erga omnes (FRANCO, 2005).

Para Carlos Roberto Gonçalves pode compreender o direito de propriedade "como o poder jurídico atribuído a uma pessoa de usar, gozar e dispor de um bem, corpóreo ou incorpóreo, em sua plenitude e dentro dos limites estabelecidos na lei, bem como de reivindicá-lo de quem injustamente o detenha" (2012, p. 194).

Verifica-se que a propriedade é uma relação social dotada de aspecto econômico protegido juridicamente, de modo que
A propriedade não é o retrato material do imóvel com as características físicas, mas a feição econômica e jurídica que a representa formalmente, dotando o proprietário de uma situação ativa que Ihe permita o trânsito jurídico de titularidades e a proteção plena do aparato jurisdicional. O título representativo da propriedade é apenas a parte visível de um bem intangível que resume um conjunto integrado e controlável de informações que circulam entre cartórios, registros, instituições financeiras e Estado, promovendo segurança e confiança intersubjetiva (FARIAS, 2015, p. 217).

Inicialmente, a principal característica da concepção de propriedade era fundada no aspecto individualista, o qual foi modificando-se com o passar dos tempos, diante da adoção constitucional do princípio da função social da propriedade, com base na predominância do interesse público e social.

No Direito Constitucional, consideram-se terras indígenas as terras tradicionais ocupadas pelos índios em caráter permanente e com usufruto exclusivo dos recursos naturais, a fim de alcançar uma plenitude de direitos para que assim se mantenha vivo o seu povo e a sua cultura, conforme preceitua o artigo 231 da Constituição. 
Os direitos acima referidos são embasados no direito de posse, pois a propriedade indígena em si é atribuída como bem da União, conforme dispõe o artigo 20, XI da Constituição da República.

Contudo, um dos maiores problemas enfrentados pelos povos indígenas no Brasil, é a invasão de terras e a dificuldade da regularização de terras indígenas. Justifica-se pela prevalência duradoura da cultura colonizadora de expulsão (LIMA, 2011, p. 77) de indígenas de suas terras para exploração máxima de recursos, objetivando lucro.

Nesse sentido:

[...] a cultura indígena não é a de um produtor rural, que quer explorar a terra do modo mais intensivo possível, obtendo a maior produção possível e, assim, o maior lucro possível. A relação do índio com a terra é uma relação de vida, de cultura, que deságua em agricultura extensiva, na coleta dos frutos da terra e no respeito. Essa incompreensão faz com que muitos considerem "absurdo" que os índios tenham tantas terras e nada façam com elas (LIMA, 2011, p. 77).

Na mesma linha o Estatuto do Índio destaca que "cabe aos índios ou silvícolas a posse permanente das terras que habitam e o direito ao usufruto exclusivo das riquezas naturais e de todas as utilidades naquelas terras existentes" (BRASIL, 1973).

Destaca-se que essa posse não se confunde com a posse de natureza civil, haja vista que não possui um viés patrimonial, mas sim uma vinculação com a própria sobrevivência física e cultural, pois "a posse das terras indígenas garante a sobrevivência dos povos e proporciona interação com o meio ambiente, permitindo o desenvolvimento equilibrado na vida humana. É por esse motivo que a posse indígena é, com razão, constitucionalmente diferenciada da posse civil" (LIMA, 2011 , p. 137).

No entanto, contrariamente ao disposto no texto constitucional acerca do usufruto exclusivo dos recursos naturais, o STF relativizou esta exclusividade, no caso Raposa Serra do Sol:

A exclusividade de usufruto das riquezas do solos, dos rios e dos lagos nas terras indígenas é conciliável com a eventual presença de não índios, bem assim com a instalação de equipamentos públicos, a abertura de estradas e outras vias de comunicação, a montagem ou construção de bases físicas para a prestação de serviços públicos ou de relevância pública, desde que tudo se processe sob a liderança institucional da União, controle do Ministério Público e atuação coadjuvante de entidades tanto da administração federal quanto representativas dos próprios indígenas. O que já impede os próprios índios e suas comunidades, por exemplo, de interditar ou bloquear estradas, cobrar pedágio pelo uso delas e inibir o regular funcionamento das repartições públicas (BRASIL, 2009). 
O artigo 22 da Constituição de 1998 estabelece a inalienabilidade das terras ocupadas pelos índios (BRASIL, 1988). Entende-se por inalienabilidade a impossibilidade de a União vender, dar ou permutar, ou até mesmo oferecer em garantia as terras indígenas (LIMA, 2011, p. 140), pois estas devem ser mantidas como patrimônio da União.

$\mathrm{O}$ artigo 23 do Estatuto do Índio considera a "posse do índio ou silvícola a ocupação efetiva da terra que, de acordo com os usos, costumes e tradições tribais, detém e onde habita ou exerce atividade indispensável à sua subsistência ou economicamente útil" (BRASIL, 1973).

Vale lembrar que a posse indígena não possui vínculo econômico, mas está pautada nos costumes, nas tradições, na cultura, na espiritualidade, nos rituais, nas crenças religiosas, na maneira de utilizar a natureza, buscando sempre uma harmonização entre o necessário para o bem-estar e a preservação do meio ambiente onde vivem.

$\mathrm{O}$ artigo 25 do Estatuto Indígena dispõe que o reconhecimento do direito dos índios e grupos tribais à posse permanente das terras por eles habitadas, independerá de sua demarcação e será assegurado pelo órgão federal de assistência aos silvícolas, atendendo à situação atual e ao consenso histórico sobre a antiguidade da ocupação (BRASIL, 1973).

Essa garantia assegurada da posse permanente independentemente de demarcação estabelece o caráter originário do índio sobre a terra. Partindo desse pressuposto, a posse indígena não está vinculada à obrigatoriedade de registro, pois a demarcação é um mero reconhecimento de um direito originário já existente.

Segundo a jurisprudência,

O direito dos povos indígenas às terras que ocupam tradicionalmente não depende de demarcação, cabendo ao Poder Público defender este direito mesmo que jamais venha a existir uma demarcação formal, como se deduz do art. 25 da Lei 6.001/73. Cabe apenas ao Juiz indagar se há provas de que a terra é tradicionalmente ocupada por indígenas e então dar-lhe a proteção devida nos termos do art. 231 da Constituição [...] (BRASIL, 2007)

O artigo 32 da Lei 6.001/73 refere-se às terras de domínio indígena, ou seja, as terras adquiridas pelos índios pelos meios formais de aquisição de propriedade, regidos pelas normas de direito civil, são as denominadas terras de domínio indígena.

O reconhecimento da terra indígena e sua posse tradicional é de fundamental importância tanto para a existência dos povos tradicionais como para o próprio meio ambiente. A questão da posse e propriedade indígena não se confunde com o direito civil, devendo ser tratada a partir do indigenato.

O indigenato é uma teoria adotada para compreensão dos direitos indígenas às terras que ocupam, a qual aborda as terras indígenas como um direito congênito, anterior ao próprio ordenamento jurídico e não está atrelado à vontade do colonizador, pois é originário (LINS JÚNIOR; LACERDA, 2017) devendo ser reconhecido pelo Estado. 
De acordo com José Afonso da Silva, o indigenato atualmente está no art. $231, \S 1^{\circ}$ da Constituição e funda-se em quatro condições: a) moradia permanente; b) uso produtivo; c) preservação dos recursos ambientais necessários a seu bem-estar; d) garantia da reprodução física e cultural, protegendo-se os usos, costumes e tradições, sendo que estas condições devem ser analisadas segundo os costumes e modo de viver indígena e não sob a visão do modo de produção capitalista vigente, ou seja, a visão não-indígena (2014, p. 871-873).

No Brasil, a teoria do indigenato teve como mentor o jurisconsulto João Mendes Júnior, que a estabeleceu em sua obra Os indigenas do Brazil, seus direitos individuaes e políticos em 1912, tratando-a como direito congênito historicamente definido

[...] Desde que os índios já estavam aldeados com cultura e morada habitual, essas terras por elles ocupadas, si já não fossem delles, tambem não poderiam ser de posteriores posseiros, visto que estariam devolutas; em qualquer hypothese, suas terras Ihes pertenciam em virtude do direito á reserva, fundado no Alvará de 1 de Abril de 1680, que não foi revogado, direito esse que jamais poderá ser confundido com uma posse sujeita á legitimação e registro (MENDES JÚNIOR, 1912, p. 57).

E de forma mais específica, o indigenato independe de legitimação e registro, pois

Por conseguinte, o indigenato não é um facto dependente de legitimação, ao passo que a ocupação, como facto posterior, depende de requisitos que a legitimem. $O$ indígena, primariamente estabelecido tem a sedum positivo, que constitue o fundamento da posse, segundo o conhecido texto do jurisconsulto Paulo (Dig., titul. de acq. vel. amiit. possess., L. 1), a que se referem Savigny, Molitor, Mainz e outros romanistas; mas o indígena, além desse jus possessionis, tem o jus possidendi, que já lhe é reconhecido e preliminarmente legitimado, desde o Alvará de 1 de Abril de 1680, como direito congênito. Ao indigenato, é que melhor se aplica o texto do jurisconsulto Paulo: - quia naturaliter tenetur $a b$ eo qui insistit. (MENDES JÚNIOR, 1912, p. 58-59)

$\mathrm{O}$ instituto do indigenato foi reconhecido pelo direito brasileiro através do alvará de $1^{\circ}$ de abril de 1680, o qual foi ratificado pela lei de 6 de junho de 1755, o qual reservou aos indígenas o direito sobre seus territórios, quando as terras da coroa foram outorgadas aos particulares (SILVA, 2014, p. 873-874).

Verifica-se então que esse princípio de reservar os direitos indígenas às terras outorgadas aos particulares reconhece a originalidade do direito territorial, o qual institui-se na tese do indigenato, significando dizer que é um direito congênito, anterior a todos os outros reconhecidos pelo ordenamento jurídico brasileiro, pois este direito é anterior ao 
próprio ordenamento (CAVALCANTE, 2016, p. 6).

Diante disso, tem-se que:

O indigenato é a fonte primária e congênita da posse territorial; é um direito congênito, enquanto a ocupação é título adquirido. O indigenato é legítimo por si, "não é um fato dependente de legitimação, ao passo que a ocupação, como fato posterior, depende de requisitos que a legitimem" (SILVA, 2014, p. 874).

E ainda:

[...] a demarcação de terras indígenas é tida tão somente como um ato declaratório do Poder Executivo Federal. Por isso, salvo em casos de criação de reservas indígenas, não há que se falar em "criação de terras indígenas", mas tão somente de seu reconhecimento por parte da União Federal. As terras indígenas, deste modo, são entendidas como tais, sendo a demarcação apenas um ato de reconhecimento do Estado. Apesar disso, tal ato assume enorme importância, pois, sem ele, os povos indígenas dificilmente conseguem ter posse plena de suas terras; mesmo quando detém a posse precária, enfrentam inúmeras dificuldades para a instalação de aparelhos destinados à prestação de serviços públicos (CAVALCANTE, 2016, p. 6-7).

Apesar desses diretos serem congênitos e originários, significando que não há criação de terras indígenas, pois estas já pertencem a eles, é função do Estado reconhecer e demarcar, a fim de garantir segurança jurídica a esses povos, pois mesmo já as possuindo, esses povos não conseguem ter pleno gozo de seus direitos de posse e usufruto.

Nota-se que o ato de demarcação pelo Poder Público é apenas um aspecto formal declaratório do direito e não de reconhecimento do direito material propriamente dito, pois o instituto do indigenato não se vale das características do direito privado, como a posse e propriedade civil, as quais necessitam de legitimação para tornarem título adquirido, mas sim de um direito congênito e originário que nasce com o próprio índio.

Apesar de a Constituição não garantir expressamente a propriedade, mas tão somente a posse e usufruto, tendo em vista que a propriedade ficou em nome da União, a finalidade foi a proteção destas terras que se tornaram indisponíveis, imprescritíveis, inalienáveis e regidas pelo indigenato.

Ademais,

[...] isso não impede a aplicação das decisões da Corte Interamericana aos casos em que se discute o direito à delimitação e demarcação dos seus territórios, com base no artigo 21, já que o fundamento no direito originário/ancestral, e os efeitos práticos do julgado da Corte são os mesmos de nossa Constituição, ou seja, o 
reconhecimento de que uma comunidade indígena faz jus a possuir e utilizar permanentemente o seu território ancestral, sobre o qual tem direito originário (LINS JÚNIOR; LACERDA, 2017, p. 265).

É necessário que haja um alinhamento convencional entre o direito pátrio e as decisões da Corte Interamericana de Direitos Humanos, razão pela qual merece atenção a decisão questionável do Supremo Tribunal Federal (STF) no caso Raposa Serra do Sol.

\section{A posição adotada pelo STF}

Ao tratar do direito de propriedade indígena, o STF, no julgamento do Caso Raposa Serra do Sol, estabeleceu dezenove condicionantes em sua decisão, como exemplo o usufruto da terra, relação entre indígenas e não-indígenas, a atuação das forças armadas, entres outras.

Além das dezenove condicionantes, fixou como critério para reconhecimento de um território como indígena o marco temporal, o qual consiste na estipulação da data da promulgação da Constituição da República, dia 5 de outubro de 1988, para a verificação de indígenas ocupantes de um determinado território.

Ao determinar esse novo critério para reconhecimento de um território indígena, o STF suprimiu o conceito de terras tradicionalmente ocupadas abarcada pela Constituição Federal, a qual rompeu o paradigma da assimilação, instituiu e valorizou o direito dos povos indígenas de se considerarem diferentes e serem respeitados como tais e reforça as suas instituições, culturas e tradições (PEREIRA, 2018, p. 85).

No tocante ao novo critério estabelecido, o Ministro Nelson Jobim destacou:

Mas a habitação permanente não é o único parâmetro a ser utilizado na identificação das terras indígenas. Em verdade, é o parâmetro para identificar a base ou núcleo da ocupação das terras indígenas, a partir do qual as demais expressões dessa ocupação devem se manifestar. Para além desse fator temporal, exigem-se na caracterização das terras indígenas, como expõe Luiz Armando Badin, os seguintes fatores: (...). b) fator econômico - as terras devem ser utilizadas para suas atividades produtivas; são os locais necessários à subsistência e produção econômica (como campos de caça, pesca, coleta e cultivo, por exemplo); c) fator ecológico - as terras devem ser imprescindíveis à preservação dos recursos naturais necessários a seu bem-estar; d) fator cultural e demográfico - as terras devem ser necessárias a sua reprodução física e cultural (manifestações culturais da comunidade, cemitérios, locais religiosos e destinados a práticas rituais), bem como a outras atividades próprias a sua organização social e econômica (BRASIL, 2009). 
Ou seja, verifica-se que com a demonstração da presença de indígenas em uma determinada área na data do dia 5 de outubro de 1998, bem como que estabelecida uma extensão geográfica, constatado as demais expressões de ocupação tradicional da terra, os direitos privados não poderão prevalecer em detrimento dos direitos indígenas, de nada importando os fatos anteriores, como a posse e a ocupação (BRASIL, 2009).

Assim, ao estabelecer o marco temporal para reconhecimento das terras indígenas, o STF fez ressalva no tocante ao esbulho renitente, o qual foi definido como:

\begin{abstract}
Renitente esbulho não pode ser confundido com ocupação passada ou com desocupação forçada, ocorrida no passado. Há de haver, para configuração de esbulho, situação de efetivo conflito possessório que, mesmo iniciado no passado, ainda persista até o marco demarcatório temporal atual (vale dizer, a data da promulgação da Constituição 1988), conflito que se materializa por circunstâncias de fato ou, pelo menos, por uma controvérsia possessória judicializada (BRASIL, 2014).
\end{abstract}

A caracterização do esbulho renitente deu-se pelo conflito possessório atual na data da promulgação da Constituição Federal de 1988, levando em conta as disputas por território que estavam ocorrendo naquele momento ou que havia retirado os indígenas há pouco tempo.

O STF, ao exigir o esbulho renitente pelos não-índios como condição para comprovação de tradicionalidade, impõe aos indígenas a resistência e ainda remete os direitos indígenas aos institutos do direito civil, como a utilização de expressões como demanda possessória (LINS JÚNIOR; LACERDA, 2017, p. 267).

Esta interpretação desvirtua e ignora o indigenato e coloca o Poder Judiciário como um fomentador de conflito por terras, depositando no índio a culpa pela perda de seu próprio território e ainda com o ônus de provar o esbulho (SILVA, 2016).

Ademais, manifestou-se, ainda, o STF no sentido de que o julgamento do Caso Raposa Serra do Sol não gera efeito vinculante para outras ações, afirmando que a tese do marco temporal tem sido utilizada para defesa de interesses contrários aos direitos às terras indígenas. No entanto, "mesmo após sua manifestação de não vinculação do julgado, o STF anulou demarcações com base na tese do marco temporal da promulgação da Constituição Federal de 1988 [...]" (APARICIO, 2018, p. 109).

Nesse sentido:

Em 23 de outubro de 2013, o Supremo Tribunal Federal (STF) julgou os embargos de declaração impetrados sobre a ação e já resolveu que a decisão sobre a Terra Indígena Raposa Serra do Sol não tem efeito vinculante. 
No entanto, mesmo antes disso, ela já vinha sendo adotada como jurisprudência por vários juízes e tribunais brasileiros, o que provavelmente continuará acontecendo. O próprio Supremo Tribunal Federal, por meio de sua segunda turma, anulou a portaria de reconhecimento da Terra Indígena Limão Verde (de ocupação tradicional Terena) com base no argumento da não observância do marco temporal de ocupação fixado em 1988 pelo julgamento citado (CAVALCANTE, 2016, p. 14).

Em relatório da missão ao Brasil, a Relatora Especial da ONU sobre os direitos dos povos indígenas destacou:

Um motivo de séria preocupação é a frequente determinação de ordens de reintegração de posse quando os povos indígenas retomam e reocupam terras a que têm direito sob a Constituição de 1988, mas que o Estado não conseguiu demarcar nos últimos 28 anos. Ainda que não necessariamente vinculante para outros casos, 14 interpretações altamente controversas e fortemente contestadas da Suprema Corte no caso Raposa Serra do Sol - que introduziu um marco temporal exigindo que os povos indígenas estivessem na posse de suas terras ou já tivessem demandas processadas quando a Constituição foi promulgada, sem consideração para como ou por que eles haviam sido retirados de suas terras - impõem restrições aos direitos dos povos indígenas de possuírem e controlarem suas terras e recursos naturais, e prejudicam a demarcação de terras (ONU, 2016, p. 15).

O fato de o STF não ter atribuído efeito vinculante à decisão que estabelece o marco temporal para reconhecimento de terras indígenas de nada tem impedido a adesão dessa interpretação para outros casos de direito à terra indígena, gerando restrições aos direitos de posse e usufruto dos recursos naturais e, ainda, corroborando com a dificuldade da demarcação de terras.

A aplicação do marco temporal contraria a Convenção Americana de Direitos Humanos, assim como decisões da Corte Interamericana. Deste modo, o Brasil por ser signatário da Convenção e ter submetido sua competência jurisdicional à Corte, poderá ser responsabilizado internacionalmente pelo desrespeito ao direito às terras indígenas, assim como o Caso do Povo Xucuru. Nesse sentido:

Ao criar regras que condicionam restritivamente o direito das comunidades indígenas brasileiras aos seus territórios tradicionais, o STF excedeu os limites de sua atuação institucional, praticando um decisionismo que contraria não só a Constituição Brasileira e a Convenção Americana, mas também as decisões da Corte 
Desta maneira, ao julgar o Caso Raposa Serra do Sol, o STF fixou novos parâmetros para a identificação de propriedade indígena, estabelecendo um marco temporal para o reconhecimento desse direito, com ressalvas ao esbulho renitente, o qual incita a violência entre as comunidades indígenas e os não-índios diante da resistência.

Também, fixou o STF que esta decisão acerca do marco temporal não geraria efeito vinculante. No entanto, além de estar sendo utilizada por outros tribunais em outros casos de direito à terra, esse entendimento contraria a Constituição Federal, a Convenção Americana e as decisões da Corte Interamericana de Direitos Humanos no tocante aos direitos de posse das terras e usufruto de seus recursos naturais.

\section{Considerações finais}

O conceito de propriedade comunal deve levar em conta a relação que os indígenas possuem com suas terras, valorizando os aspectos especiais que esses povos possuem com elas, devendo considerar a ancestralidade, a valorização do patrimônio cultural desses povos, além de suas atividades produtivas e suas reproduções.

Assim, a propriedade indígena não se confunde com a propriedade privada, pois ela é direito fundamental, coletiva, indisponível, imprescritível, inviolável, intransigível, universal, originária e congênita. Enquanto a propriedade civil é direito patrimonial, individualista, excludente, disponível, negociável, alienável, acumulativa, pode ser constituída, modificada ou extinta.

Ademais, o direito às terras é originário e congênito, sendo que o instituto que melhor interpretou essa questão no Brasil foi a teoria do indigenato, por tratar das peculiaridades que esses povos possuem com suas terras e que possui maior compatibilidade com a interpretação da Corte Interamericana em relação ao Caso Xucuru.

No entanto, esse instituto nem sempre é aplicado no Brasil, muitas vezes prevalecendo a interpretação da propriedade comunal como uma propriedade privada do instituto do direito civil, o que remete a esses povos uma grande dificuldade no pleno uso e gozo desse direito às terras, por ter que enfrentar questões completamente distintas de suas tradições e culturas, pautadas no individualismo, no valor pecuniário, na exploração máxima para obtenção de riquezas, gerando insegurança jurídica.

Por isso, ao analisar o conceito da propriedade coletiva nos documentos internacionais, bem como o julgado da Corte Interamericana, verificou-se que se trata de um espaço indispensável aos povos indígenas para utilização em suas atividades produtivas, que são imprescindíveis para a preservação dos recursos ambientais e necessária ao bem estar desses povos e suas reproduções físicas, culturais e espirituais, de acordo com seus usos, costumes e tradições, fundamentada, de acordo com a Corte, em sua ancestralidade. 
O direito de posse permanente abordado pelo art. 231 da Constituição não tem sido efetivo diante da interpretação judicial que tem recebido, como, por exemplo, a teoria do marco temporal adotada pelo STF.

A teoria do marco temporal criada pelo STF colide frontalmente com o conceito de propriedade comunal, pois supre o conceito de terras tradicionalmente ocupadas, além de contrariar 0 aspecto da ancestralidade, gerando insegurança jurídica num cenário em que há graves e violentos conflitos fundiários.

Ademais, a fixação de uma data para o reconhecimento de uma terra como indígena contraria os atributos do instituto do indigenato, pois como defendido nessa teoria, o direito às terras é anterior ao próprio ordenamento jurídico, pois é inerente aos povos indígenas.

Esses aspectos abarcados pelo instituto do indigenato são totalmente compatíveis com a decisão da Corte Interamericana e sua jurisprudência evolutiva acerca do conceito de propriedade coletiva, no sentido de comunal.

Nesta linha, a Corte Interamericana condenou o Brasil por violar esse direito à propriedade comunal e impôs ao Estado brasileiro na criação de um fundo de desenvolvimento comunitário como compensação pelo dano aos Povos Xucurus e fixou indenização no valor de US\$1.000.000,00 (um milhão de dólares dos Estados Unidos da América) para a constituição do referido fundo, a serem pagos no prazo de dois anos.

Além disso, determinou que o Estado brasileiro tomasse medidas imediatas e efetivas para garantir o direito de propriedade coletiva ao Povo Indígena Xucuru, ao passo que não permitam que sofram invasões, interferências ou danos por terceiros não indígenas, ou pelo próprio Estado. E deverá concluir o procedimento de desintrusão de terceiros no território indígena Xucuru e efetuar o pagamento das indenizações por benfeitorias de boa-fé, de modo a garantir domínio pleno e efetivo desses povos em seu território, também no prazo de dois anos, contados da publicação da sentença.

Destarte, apesar de o Brasil possuir a teoria do indigenato, na mesma base do conceito de propriedade comunal da Corte Interamericana, faz-se necessário que estes institutos garantidores dos direitos indígenas recebam uma interpretação e aplicação corretas, de forma constitucional e convencional, alinhando-se direito nacional e internacional na tutela e dignidade destes povos originários.

Assim, a partir desta condenação, espera-se do Brasil um maior comprometimento na defesa dos direitos indígenas, principalmente no tocante ao direito às terras e na interpretação de maneira evolutiva do conceito de propriedade comunal, além de maior efetividade nos procedimentos demarcatórios, tendo em vista que estes, apesar de na teoria não serem imprescindíveis à garantia do direito às terras, tornaramse necessários para que tais direitos sejam implementados. 


\section{Referências bibliográficas}

APARICIO, Adriana Biller. O instituto do indigenato e teoria crítica: a possibilidade de reinvenção do fundamento jurídico dos direitos territoriais indígenas a partir da análise da territorialidade e dos processos de luta Guarani. 2018. Tese (Pós-Graduação em Direito) - Universidade Federal de Santa Catarina. Florianópolis, 2018. Disponível em: https://repositorio.ufsc.br/bitstream/handle/123456789/189500/PDPC1363T.pdf? sequence=-1\&isAllowed=y. Acesso em: 5 ago. 2019.

BRASIL. [Constituição (1988)]. Constituição da República Federativa do Brasil de 1988. Brasília, DF: Presidência da República, [2020]. Disponível em: http://www.planalto.gov.br/ccivil_03/constituicao/constituicao.htm. Acesso em: 6 nov. 2020.

BRASIL. Decreto de 30 de abril de 2001. Homologa a demarcação administrativa da Terra Indígena Xucuru (Xukuru), localizada no Município de Pesqueira, Estado do Pernambuco. Brasília, DF: Presidência da República, [2001]. Disponível em: http://www.planalto.gov.br/ccivil_03/DNN/2001/Dnn9198.htm. Acesso em: 10 abr. 2019.

BRASIL. Fundação Nacional do Índio. Comunicação: notícias. Brasília, DF, [2016]. Disponível em: http://www.funai.gov.br/index.php/comunicacao/noticias/3815-oea. Acesso em: 17 out. 2020.

BRASIL. Lei $\mathrm{n}^{0}$ 6.001, de 19 de dezembro de 1973. Dispõe sobre o Estatuto do Índio. Brasília, DF: Presidência da República, [1973]. Disponível em: http://www.planalto.gov.br/ccivil_03/LEIS/L6001.htm. Acesso em: 27 maio 2019.

BRASIL. Supremo Tribunal Federal. Agravo Regimental No Recurso Extraordinário Com Agravo 803.462. Constitucional e Administrativo. Terra Indígena "Limão Verde". Área Tradicionalmente Ocupada Pelos Índios (Art. 231, § 1º Da Constituição Federal). Marco Temporal. Promulgação Da Constituição Federal. Não Cumprimento. Renitente Esbulho Perpetrado Por Não Índios: Não Configuração. Agravante: Tales Oscar Castelo Branco. Agravado: União; Ministério Público Federal; FUNAI - Fundação Nacional Do Índio. Relator: Min. Teori Zavascki, Brasília, 9 de dezembro de 2014.

BRASIL. Supremo Tribunal Federal. Pet 3.388. Requerente: Augusto Affonso Botelho Neto. Requerido: União. Relator: Min. Ayres Britto, Brasília,19 de março de 2009.

BRASIL. Tribunal Regional Federal (1. Região). Apelação Cível 200101000365819. Ação Civil Pública. Direito À Posse De Terra Indígena. Interdição De Área - Natureza Verdadeira Do Pedido. Índios Isolados. Relator: Desembargador Federal Cesar Augusto Bearsi, Brasília, 03 de outubro de 2007.

CAVALCANTE, Thiago Leandro Vieira. "Terra Indígena": aspectos históricos da construção e aplicação de um conceito jurídico. História, Franca, v. 35, p. 1-22, jul. 2016. Disponível em: https://www.scielo.br/pdf/his/v35/0101-9074-his-35-00075.pdf. Acesso em: 28 ago. 2020.

FARIAS, Cristiano Chaves de; ROSENVALD, Nelson. Curso de Direito Civil. 11. ed. 
Espaço Ameríndio

São Paulo: Atlas, 2015.

FRANCO, Wanildo José Nobre. A posse e a propriedade. Boletim Jurídico, Uberaba, nov. 2005. Disponível em: https://www.boletimjuridico.com.br/ doutrina/artigo/1024/aposse-propriedade. Acesso em: 09 nov. 2020.

GREGÓRIO, Fernando da Silva. Consequências Sistêmicas da Soft Law para a evolução do Direito Internacional e o reforço da Regulação Global. Revista de Direito Constitucional e Internacional, v. 24, n. 95, p. 01-10, abr.-jun., 2016.

GONÇALVES, Carlos Roberto. Direito civil brasileiro: direito das coisas. 7. ed. São Paulo: Saraiva, 2012. v.5.

HEEMANN, Thimotie Aragon. Por uma Releitura do Direito Dos Povos Indígenas: do integracionismo ao interculturalismo. Revista de Doutrina e Jurisprudência, Brasília, v. 109, n. 101, p. 1-14, jul.- dez, 2017.

LIMA, Edilson Vitorelli Diniz. Estatuto do Índio: lei n 6.001/73. Salvador: Jus Podivm, 2011. v. 33.

LINS JÚNIOR, George Sarmento; LACERDA, Danilo Moura. O Direito de propriedade na Convenção Americana de Direitos Humanos e a superação da condição do marco temporal da posse indígena criada pelo STF, no caso "Raposa Serra do Sol". Revista Jurídica Direito \& Paz, Lorena, v. 9, n. 37, p. 253-272, 2017. Disponível em: http://www.revista.unisal.br/lo/index.php/direitoepaz/article/view/728. Acesso em: 09 nov. 2020.

MATHIAS, Fernando; YAMADA, Erika. Povos Indígenas no Brasil. Declaração da ONU sobre direitos dos povos indígenas, São Paulo, abril 2010. Disponível em: https://pib.socioambiental.org/pt/Declara\%C3\%A7\%C3\%A3o_da_ONU_sobre_direitos _dos_povos_ind\%C3\%ADgenas. Acesso em: 09 nov. 2020.

MENDES JÚNIOR, João. Os indigenas do Brazil, seus direitos individuaes e politicos. São Paulo: Typ. Hennies Irmãos, 1912. Disponível em: https://cpisp.org.br/publicacao/osindigenas-do-brazil-seus-direitos-individuaes-e-politicos/. Acesso em: 09 nov. 2020.

OEA. Convenção Americana Sobre Direitos Humanos. San José: Costa Rica, 22 de novembro de 1969.1 Disponível em: https://www.cidh.oas.org/basicos/portugues/c.convencao_americana.htm. Acesso em: 11 set. 2019.

OEA. Corte Interamericana de Direitos Humanos. Sentença. Caso da Comunidade Mayagna (Sumo) Awas Tingni vs. Nicarágua. Presidente: Antônio A. Cançado Trindade, San José: Costa Rica, 31 de agosto de 2001. Disponível em: http://www.cnj.jus.br/files/conteudo/arquivo/2016/04/1d066bbac6f06f20e3bb0e08e569 7c4a.pdf. Acesso em: 15 abr. 2019.

OEA. Corte Interamericana de Direitos Humanos. Sentença. Caso do Povo Indígena Xucuru e seus membros vs. Brasil. Presidente: Eduardo Ferrer Mac-Gregor Poisot, San José: Costa Rica, 5 de fevereiro de 2018. Disponível em: 
http://www.corteidh.or.cr/docs/casos/articulos/seriec_346_por.pdf. Acesso em: 11 set. 2019.

OEA. Declaração Americana sobre os Direitos dos Povos Indígenas. Aprovada na terceira sessão plenária, realizada em 15 de junho de 2016. Santo Domingo: República Dominicana, 15 de junho de 2016. Disponível em: https://www.oas.org/en/sare/documents/DecAmIND_POR.pdf. Acesso em: 17 abr. 2019.

OIT. Convenção n 169 da OIT sobre Povos Indígenas e Tribais. Genebra, 7 de junho de $1989 . \quad$ Disponível em: https://www.oas.org/dil/port/1989\%20Conven\%C3\%A7\%C3\%A3o\%20sobre\%20Povos $\% 20$ Ind $\%$ C3\%ADgenas $\% 20 \mathrm{e} \% 20$ Tribais $\% 20$ Conven $\%$ C3\%A7\%C3\%A3o\%20OIT\%2 0n\%20\%C2\%BA\%20169.pdf. Acesso em: 08 nov. 2020.

ONU. Declaração das Nações Unidas sobre os direitos dos povos indígenas. Nova Iorque, 13 de setembro de 2007. Disponível em: https://pib.socioambiental.org/files/file/PIB_institucional/DECLARACAO_DAS_NAC OES_UNIDAS_SOBRE_OS_DIREITOS_DOS_POVOS_INDiGENAS.pdf. Acesso em: 09 nov. 2020.

ONU. Conselho de Direitos Humanos. Relatório da missão ao Brasil da Relatora Especial sobre os direitos dos povos indígenas. Assembleia Geral, 8 de agosto de 2016. Disponível em: http://webcache.googleusercontent.com/search?q=cache:hFxj0rAnsPkJ:www.mpf.mp.br /atuacao-tematica/ccr6/documentos-e-publicacoes/docs/relatorio-onu-povosindigenas/relatorio-onu-2016_pt.pdf/at_download/file+\&cd=2\&hl=ptBR\&ct $=$ clnk\&gl=br. Acesso em: 01 nov. 2020.

PEREIRA, Deborah Macedo Duprat de Britto. O marco temporal de 5 de outubro de 1988: Terra Indígena Limão Verde. In: ALCÂNTARA, Gustavo Kenner; TINÔCO, Lívia Nascimento; MAIA, Luciano Mariz (Coord.). Índios, Direitos Originários e Territorialidade. Brasília: ANPR, 2018.

SCHETTINI, Andrea. Por um novo paradigma de proteção dos direitos dos Povos Indígenas: uma análise crítica dos parâmetros estabelecidos pela corte interamericana de direitos humanos. Revista Internacional de Direitos Humanos, São Paulo, v. 9, n. 17, p. 63-85, dez. 2012.

SILVA, José Afonso. Curso de Direito Constitucional Positivo. 37. ed. São Paulo: Malheiros Editores, 2014.

SILVA, José Afonso de. Parecer sobre o Marco Temporal de 1988. Brasília: DF, maio 2016. Disponível em:_http://www.mpf.mp.br/atuacao-tematica/ccr6/documentos-epublicacoes/artigos/docs_artigos/jose-afonso-da-silva-parecer-maio-2016-1.pdf. Acesso em: 15 out. 2020.

TERRA DE DIREITOS. Terra é vida, não mercadoria: direitos e mecanismos nacionais. ActionAid, Rio de Janeiro, 2015. Disponível em: http://actionaid.org.br/wpcontent/files_mf/1493418923direito_terra_actionaid_1e.pdf. Acesso em: 09 nov. 2020. 
Recebido em: 18/08/2021 * Aprovado em: 10/11/2021 * Publicado em: 23/12/2021 